Article

\title{
An Innovative Device to Convert Olive Mill Wastewater into a Suitable Effluent for Feeding Purple Non-Sulfur Photosynthetic Bacteria
}

\section{Pietro Carlozzi ${ }^{1, *}$, Giulia Padovani ${ }^{1}$, Patrizia Cinelli ${ }^{2,3}$ and Andrea Lazzeri ${ }^{3}$}

1 Istituto per lo Studio degli Ecosistemi, Sede di Firenze, Consiglio Nazionale delle Ricerche, Polo Scientifico, Sesto Fiorentino 50019, Firenze, Italy; E-Mail: g.padovani@ise.cnr.it

2 Istituto per i Processi Chimico-Fisici, Consiglio Nazionale delle Ricerche, Unità di Pisa, Via Moruzzi 1, Pisa 56126, Italy; E-Mail: patrizia.cinelli@ipcf.cnr.it

3 Consorzio Interuniversitario Nazionale per la Scienza e Tecnologia dei Materiali (INSTM) c/o Dipartimento di Ingegneria Civile e Industriale, Università degli Studi di Pisa, Pisa 56126, Italy; E-Mail: a.lazzeri@diccism.unipi.it

* Author to whom correspondence should be addressed; E-Mail: p.carlozzi@ise.cnr.it; Tel.: +39-055-5225962; Fax: +39-055-5225920.

Academic Editor: Damien Giurco

Received: 6 June 2015 / Accepted: 12 August 2015 / Published: 19 August 2015

\begin{abstract}
A device (prototype) with a working volume of $200 \mathrm{~L}$ was used to deplete olive mill wastewater (OMW) of polyphenols. The OMW transformed into feedstock by means of the device was then used for feeding a lab-scale photobioreactor, just for testing the production of $\mathrm{bioH}_{2}$. The main novelty of this prototype consists in the combination of several adsorbent matrices and the exploitation of their synergic action. In this investigation, three matrices have been used: active carbon, Azolla and zeolite. The device was operated at an olive oil company located in the heart of the Chianti zone (Province of Florence, Italy). The efficiency of polyphenol removal obtained using the device was $\geq 96 \%$. The multi-matrix effluent ( $\mathrm{MM}_{\text {eff }}$ ) generated was then used to obtain three different culture broths containing $25 \%, 50 \%$ and $100 \%$ of MMeff, respectively. The diluted (with water) culture broths were suitable for hydrogen generation, with the highest hydrogen production rate (12.7 $\mathrm{mL} \mathrm{H} / \mathrm{L}_{\text {culture }} / \mathrm{h}$ ) being obtained using 50\% MMeff. The hydrogen yields were: $334 \mathrm{~mL}$ $\mathrm{H}_{2} / \mathrm{L}$ of MMeff, when feeding the photofermenter with pure effluent $(100 \%) ; 1308 \mathrm{~mL} \mathrm{H}_{2} / \mathrm{L}$ of MMeff, with the half-diluted effluent $(50 \%, \mathrm{v} / \mathrm{v})$; and $432 \mathrm{~mL} \mathrm{H} / \mathrm{L}$ of $\mathrm{MM}_{\text {eff, with }}$ the highest-diluted effluent $(25 \%, \mathrm{v} / \mathrm{v})$.
\end{abstract}


Keywords: olive mill wastewater; pretreatment; dephenolization; adsorbent matrices; feedstock; hydrogen photo-production; Rhodopseudomonas palustris

\section{Introduction}

Approaches to the use of waste materials as feed for efficient hydrogen production processes have been widely studied [1,2]. In particular, pre-treated olive mill wastewater (OMW) has been proposed as a precursor for obtaining a suitable feedstock for the photo-production of hydrogen [3-5]. Moreover, studies in the field of OMW valorization have proven that integrated biorefining concepts can effectively convert OMW components into a group of desired products, as reported by ElMekawy et al. [6]. The OMW organic fraction includes sugars, tannins, polyalcohols, pectins, lipids and polyphenols (PPs) [7], with the black-to-brownish color of OMW arising from the PP compounds. In fact, the content of these latter biomolecules is the primary cause of the phytotoxic and antimicrobial effects of OMW. Their inhibitory effect on bacterial growth makes the direct biological treatment of OMW challenging, as discussed by El Hajjouji et al. [8].

Several efforts have focused on anaerobic treatments because of its potential for the production of biofuels [9]. However, conventional anaerobic digestion of OMW exhibits well-known problems that are related to the characteristics of OMW: low alkalinity and $\mathrm{pH}$; lack of ammonium nitrogen; high chemical oxygen demand (COD), up to $200 \mathrm{~g} \mathrm{COD} / \mathrm{L}$; and a high content of PPs (15.0 g/L), as reported elsewhere $[10,11]$. Fermentative hydrogen production is attractive, since it can target various waste streams so that fuel production can potentially be coupled with a waste-treatment process where the attendant waste treatment benefits increase the overall economies [12].

Photofermentative hydrogen production has been suggested as one of the most promising hydrogen production processes, because photofermentation produces renewable energy and purified wastewater concurrently, as has been widely discussed [5,13,14]. A recent investigation demonstrated that stored OMW can be turned into a feedstock for hydrogen photo-production following PP removal (dephenolization) by means of a pretreatment process involving the use of adsorbent matrices [15]. Moreover, a bio-refinery procedure (pretreatment first and subsequent photo-fermentation) is a suitable clean-up process that can alleviate environmental problems caused by OMW. Still, the high PP content in OMW remains a considerable problem relative to the use the effluent as feedstock. Even if hydrogen photoproduction from non-treated OMW diluted with water $(<5 \%$; v/v) has been reported by Eroğlu et al. [16], dephenolization of OMW is still desirable before using the effluent as a feedstock to produce $\mathrm{bioH}_{2}$ via photofermentation.

Photo-assisted hydrogen generation from aqueous solutions is a key scientific and technological challenge for the conversion of solar radiation into fuels meeting the current demand for clean and renewable energy sources [17]. Attainment of this goal requires a multifactorial approach using hi-tech engineering processes to handle the OMW. If we disregard artificial photo-assisted hydrogen generation, we are left with two different light-dependent processes: (i) water biophotolysis, using cyanobacteria and green algae; and (ii) photo-fermentation of organic compounds using photosynthetic bacteria [18]. In contrast to the biophotolysis process, purple non-sulfur photosynthetic bacteria (PNSB) are able to 
generate hydrogen from organic substrates through photo-fermentation [19]. The performance of various light-driven photofermentative hydrogen production schemes using PNSB has recently been described along with several developments related to batch, repeated batch, fed-batch and continuous operation [20].

Photo-fermentation is a potentially promising method compared to other microbial systems. The advantages of this process include: (i) a high substrate conversion rate; (ii) the absence of oxygen inhibition; (iii) the use of a wider wavelength band of light; and (iv) the ability to use waste organic substrates for biohydrogen production as reported by Gupta et al. [21]. Photosynthetic bacteria evolve molecular $\mathrm{H}_{2}$, which is catalyzed by nitrogenase under nitrogen-deficient conditions by using light energy and reduced compounds (organic acids) [22]. Under anaerobic conditions, these bacteria use simple organic acids (such as acetic acid) as electron donors. The electrons are transported to the nitrogenase by ferredoxin using ATP as an energy source. In the absence of nitrogen, the nitrogenase enzyme can reduce protons into $\mathrm{H}_{2}$ gas [23]. PNSB can also produce hydrogen growing on various agro-industrial byproducts, thus facilitating waste recycling and bioremediation, as reported by Redwood et al. [24].

In the present study, a device (prototype) is proposed for the dephenolization of OMW in order to generate a feedstock allowing enhanced efficiency of hydrogen photo-evolution in photobioreactors. In order to reach this goal, three different adsorbing matrices were selected and then used in the device. The selected matrices were innovatively applied, in a sequential fashion, in order to achieve a synergic adsorbent action for transforming OMW into a feedstock suitable for generating $\mathrm{bioH}_{2}$. The new prototype was designed to attain a suitable $\mathrm{MM}_{\text {eff }}$ that could be used, either pure or diluted with water, for feeding PNSB.

\section{Results}

Figure 1 shows a schematic of the device used for OMW dephenolization.

The pretreatment process consisted of phases of sequential adsorption performed using the new prototype, in which three different matrices worked together to adsorb PPs. The amount of PPs decreased from an initial value of $4.23 \mathrm{~g} / \mathrm{L}$ to a final one of $0.15 \mathrm{~g} / \mathrm{L}$. The main characteristics of the centrifuged stored OMW are shown in Table 1.

Table 1. Characteristics of stored olive mill wastewater (OMW).

\begin{tabular}{ccccc}
\hline Stored OMW & PPs (g/L) & COD $(\mathbf{g} / \mathbf{L})$ & Color $\left(\mathbf{A B S}_{395)}\right)$ & $\mathbf{p H}$ \\
\hline Before pretreatment & $4.23 \pm 0.12$ & $66.00 \pm 2.1$ & $9.35 \pm 0.22$ & $4.20 \pm 0.1$ \\
After pretreatment & $0.15 \pm 0.03$ & $23.36 \pm 1.4$ & $1.04 \pm 0.01$ & $5.26 \pm 0.1$ \\
\hline
\end{tabular}

Note: * The $\mathrm{ABS}_{395}$ was measured in a 1-cm path-length of light using samples diluted to the absorbance value of 0.10 to 1.0 .

The $\mathrm{pH}$ increased from 4.20 to 5.26. The capacity of the matrices (GAC + Azolla + zeolite) to adsorb PPs, COD and color is shown in Figure 2. 


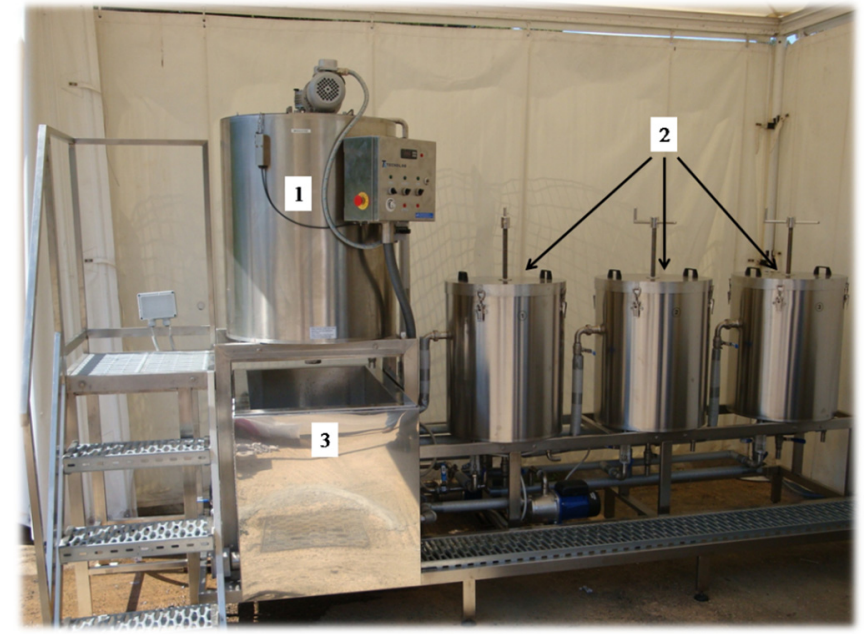

(a)

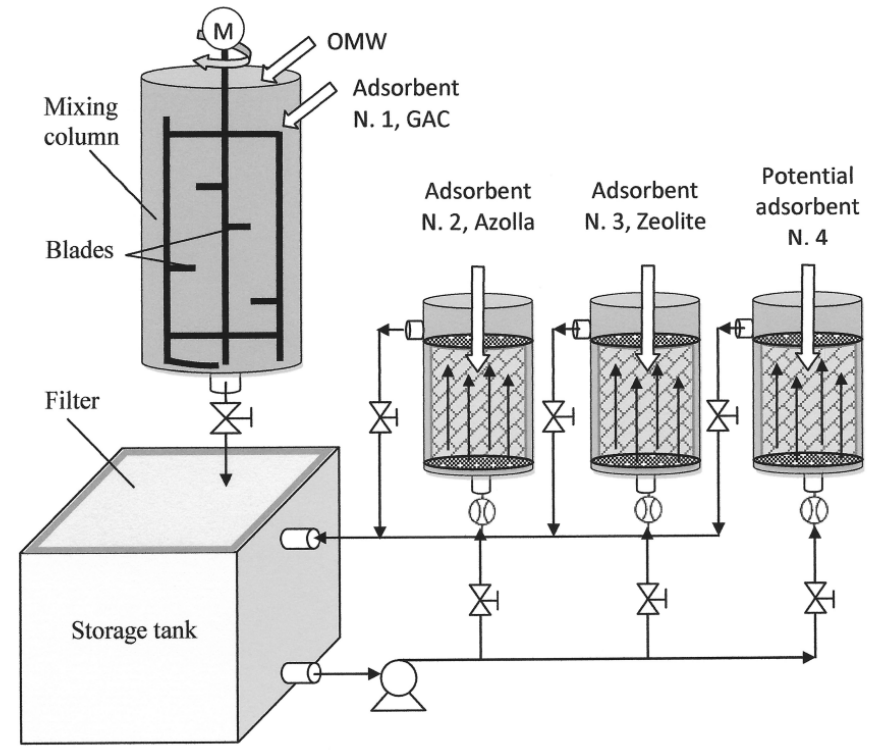

(b)

Figure 1. Picture of the device (a) and schematic of it (b). The device consists of three main components: a mixing column with blades (1), three adsorbent columns (2) and a storage tank with a filter on the top side (3).

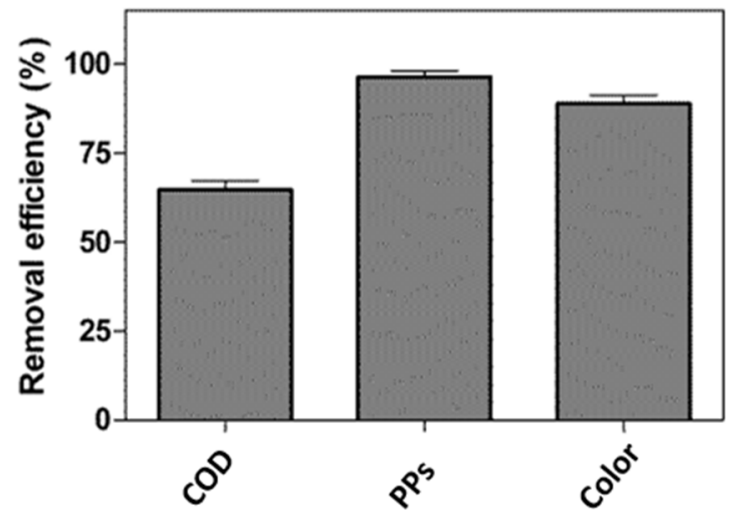

Figure 2. Efficiency of the removal of biocompounds from stored OMW by means of the new prototype. 
The PP removal efficiency was greater than $96 \%$. After this treatment, a suitable MMeff was attained that could be used for feeding PNSB. The experiments for the production of biofuels, using either pure or diluted MMeff, were then performed in a cylindrical-glass photobioreactor. In the present study, two different experiments were carried out. In the first, the culture broths containing $100 \%, 50 \%$ and $25 \%$ of MMeff were used for hydrogen generation, while in the second, $0.65 \mathrm{~g} / \mathrm{L}$ of $\mathrm{NH}_{4} \mathrm{Cl}$ were added to the culture broth containing undiluted $\mathrm{MM}_{\mathrm{eff}}$, in order to inhibit the nitrogenase and, consequently, the generation of hydrogen. In the latter case, the productivity of dry biomass and its chemical composition were also investigated.

The results regarding both the growth of Rhodopseudomonas (R.) palustris sp. and the generation of hydrogen using MMeff diluted with water (25\% and 50\%, v/v) and undiluted MMeff $(100 \%)$ are shown in Figure 3.

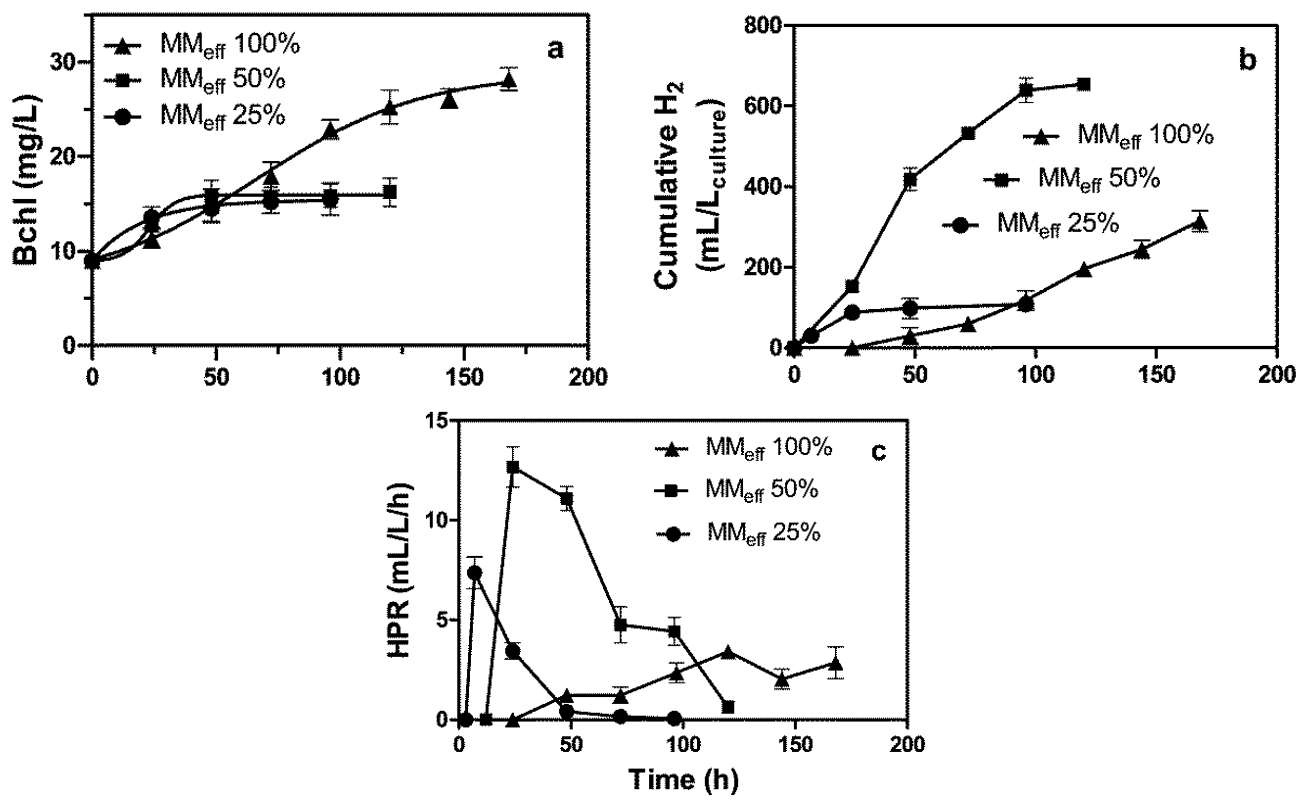

Figure 3. Growth trends of $R$. palustris sp. versus time: (a) bacteriochlorophyll (Bchl); (b) cumulative $\mathrm{H}_{2}$; and (c) hydrogen production rate (HPR). The photobioreactor was fed with undiluted $\mathrm{MM}_{\mathrm{eff}}$ or diluted $\mathrm{MM}_{\mathrm{eff}}$ with water $(25 \%$ and $50 \%$, v/v).

A moderate Bchl concentration (about $\left.16 \mathrm{mg} \cdot \mathrm{L}^{-1}\right)$ was reached when diluted MMeff $(25 \%$ and $50 \%)$ was used for feeding the photobioreactor. However, when pure MMeff was used, the Bchl concentration grew more strongly, reaching $28.2 \mathrm{mg} / \mathrm{L}$. In the case of feeding the reactor with one diluted MMeff $(50 \%$, $\mathrm{v} / \mathrm{v})$, the cumulative $\mathrm{H}_{2}$ volume was very high $\left(654 \mathrm{~mL} \mathrm{H}_{2} / \mathrm{L}_{\text {culture }}\right)$; it was much less when either pure MMeff or diluted MMeff $(25 \%$, v/v) was used (Figure $3 b)$.

A very different result was achieved relative to the hydrogen production rate (HPR). In the first case (i), when feeding the photobioreactor with diluted MMeff $(50 \%, \mathrm{v} / \mathrm{v})$, the highest HPR of $12.7 \mathrm{~mL}$ $\mathrm{H}_{2} / \mathrm{L}_{\text {culture}} / \mathrm{h}$ was attained. In the second (ii), when feeding the photobioreactor with diluted MMeff (25\%, v/v), the HPR was only $7.4 \mathrm{~mL} \mathrm{H}_{2} / \mathrm{L}_{\text {culture }} / \mathrm{h}$; and in the third case (iii), when feeding the photobioreactor with pure MMeff, the HPR was dramatically reduced, demonstrating the lowest value of $3.4 \mathrm{~mL} \mathrm{H} / \mathrm{L}_{\text {culture/h }}$ (Figure $3 \mathrm{c}$ ). This result could be attributed to the presence of a potential unknown concentrated compound (in pure $\mathrm{MM}_{\mathrm{eff}}$ ), which caused the inhibition of nitrogenase and, as a 
consequence, the transport of electrons to the nitrogenase by ferredoxin, which was required in order to reduce protons to $\mathrm{H}_{2}$ gas [23]. The results relative to $\mathrm{Bchl}$ culture combined with pure MMeff indicate clearly that $R$. palustris cells are active for growing, but are limited as far as hydrogen generation is concerned (Figure 3). In addition, both the Bchl and dry biomass trends indicated active microorganism when growing in pure MMeff to which ammonium chloride had been added. Some differences were also observed with regard to the length of the lag phase that was observed before the initiation of the hydrogen evolution (Figure 3b); the higher the amount of MMeff in the culture broth, the longer the lag phase. The MMeff, which contained organic acids, was primarily converted into $\mathrm{bioH}_{2}$, even if lipid-rich biomasses were co-produced, as well (Table 2).

Table 2. Biomass composition, dry biomass production and yields of $R$. palustris sp. grown by feeding the photobioreactor with the culture broths containing undiluted MMeff $(100 \%)$ and diluted with water $(25 \%$ and $50 \%, \mathrm{v} / \mathrm{v})$. Data relative to culture broth containing undiluted MMeff, with the addition of $0.65 \mathrm{~g} / \mathrm{L}$ of $\mathrm{NH}_{4} \mathrm{Cl}$, are also shown.

\begin{tabular}{|c|c|c|c|c|c|c|c|}
\hline Culture broths & $\begin{array}{c}\text { Proteins } \\
(\%) \\
\end{array}$ & $\begin{array}{c}\text { Carbohydrates } \\
(\%) \\
\end{array}$ & $\begin{array}{c}\text { Lipids } \\
(\%) \\
\end{array}$ & $\begin{array}{c}\text { Ashes } \\
(\%) \\
\end{array}$ & $\begin{array}{c}\text { Dry Biomass } \\
\text { Production (mg/L) }\end{array}$ & 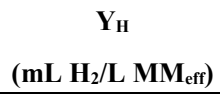 & 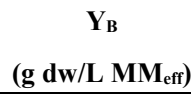 \\
\hline $\mathrm{MM}_{\mathrm{eff}} 25 \%$ & $48.3 \pm 1.9$ & $10.3 \pm 0.7$ & 29.9 & $13.6 \pm 1.1$ & $570 \pm 15$ & $43 \pm 00$ & $2.28 \pm 0.06$ \\
\hline $\mathrm{MM}_{\mathrm{eff}} 50 \%$ & $42.6 \pm 2.1$ & $14.2 \pm 1.0$ & $28.7 *$ & $14.5 \pm 1.5$ & $580 \pm 25$ & $1308 \pm 35$ & $1.16 \pm 0.05$ \\
\hline $\mathrm{MM}_{\mathrm{eff}} 100 \%$ & $43.2 \pm 2.4$ & $11.2 \pm 0.6$ & $28.3 *$ & $17.3 \pm 1.3$ & $1060 \pm 45$ & $334 \pm 15$ & $1.06 \pm 0.03$ \\
\hline $\mathrm{MM}_{\text {eff }} 100 \%+\mathrm{NH}_{4} \mathrm{Cl}$ & $42.6 \pm 1.5$ & $13.8 \pm 0.9$ & 22.7 & $18.8 \pm 1.1$ & $1840 \pm 50$ & - & $1.84 \pm 0.07$ \\
\hline
\end{tabular}

Note: * The percentage of lipids in dry biomasses was determined as follows: lipids $(\%)=100-$ (proteins + carbohydrates + ashes).

The composition of the bacterial biomasses attained by growing $R$. palustris during all of the runs tested is reported in Table 2. The protein content, as measured by the Lowry method, was the highest $(48.3 \%)$ when the photobioreactor was fed using diluted $M_{\text {eff }}(25 \%, v / v)$; on the contrary, the carbohydrate content was the lowest (10.3\%). An inverse relationship between these two classes of substances was also found by feeding the photobioreactor with diluted $\mathrm{MM}_{\mathrm{eff}}(50 \%$, v/v): 42.6\% Lowry proteins and $14.2 \%$ carbohydrates. Some differences were also found in the biomasses of $R$. palustris grown in pure $\mathrm{MM}_{\text {eff }}(100 \%)$ with and without $\mathrm{NH}_{4} \mathrm{Cl}$. The hydrogen yield $\left(\mathrm{Y}_{\mathrm{H}}\right)$ and the biomass yield $\left(\mathrm{Y}_{\mathrm{B}}\right)$ were also determined, and the results are shown in Table 2. By feeding the photobioreactor with diluted $\mathrm{MM}_{\mathrm{eff}}(50 \%, \mathrm{v} / \mathrm{v})$, the highest $\mathrm{Y}_{\mathrm{H}}$ was obtained $\left(1308 \mathrm{~mL} \mathrm{H} / \mathrm{L}\right.$ of $\left.\mathrm{MM}_{\mathrm{eff}}\right)$. The $\mathrm{Y}_{\mathrm{H}}$ decreased by a factor of 2.4 with diluted $\mathrm{MM}_{\mathrm{eff}}(25 \%, \mathrm{v} / \mathrm{v})$ and by about 3.1 when pure MMeff was fed to the photobioreactor.

The highest $\mathrm{Y}_{\mathrm{B}}(2.28 \mathrm{~g} \mathrm{dw} / \mathrm{L}$ of MMeff) was obtained by feeding the photobioreactor with diluted $\mathrm{MM}_{\mathrm{eff}}(25 \%)$. That result implied that the metabolism of the bacterium was principally directed towards protein synthesis or, more in general, towards biomass production, instead of hydrogen evolution (Table 2). An inverse behavior was found by feeding the reactor with diluted $\mathrm{MM}_{\mathrm{eff}}(50 \%, \mathrm{v} / \mathrm{v})$, where the higher $\mathrm{Y}_{\mathrm{H}}$, the lower was the $\mathrm{Y}_{\mathrm{B}}$. When $R$. palustris sp. grew in the culture broth containing pure MMeff with the addition of $\mathrm{NH}_{4} \mathrm{Cl}$, the hydrogen evolution being inhibited by ammonium, the metabolism involved biomass synthesis, and $\mathrm{Y}_{\mathrm{B}}$ increased 1.7 times.

The ash content in dry-biomass was always higher than $13 \%$, and its content increased in accordance with the amount of MMeff in the culture broth; the higher the percentage of MMeff in the culture broth, 
the higher the content of ash. Achak et al. [25] attributed such high ash content in the resulting biomasses to the high amount of $\mathrm{Al}, \mathrm{Mg}, \mathrm{Ca}, \mathrm{Fe}, \mathrm{Sr}, \mathrm{Pb}$ and $\mathrm{Li}$ in $\mathrm{OMW}$.

The consumption of VFAs and COD was also evaluated during $\mathrm{bioH}_{2}$ generation, and the results are shown in Figure 4.
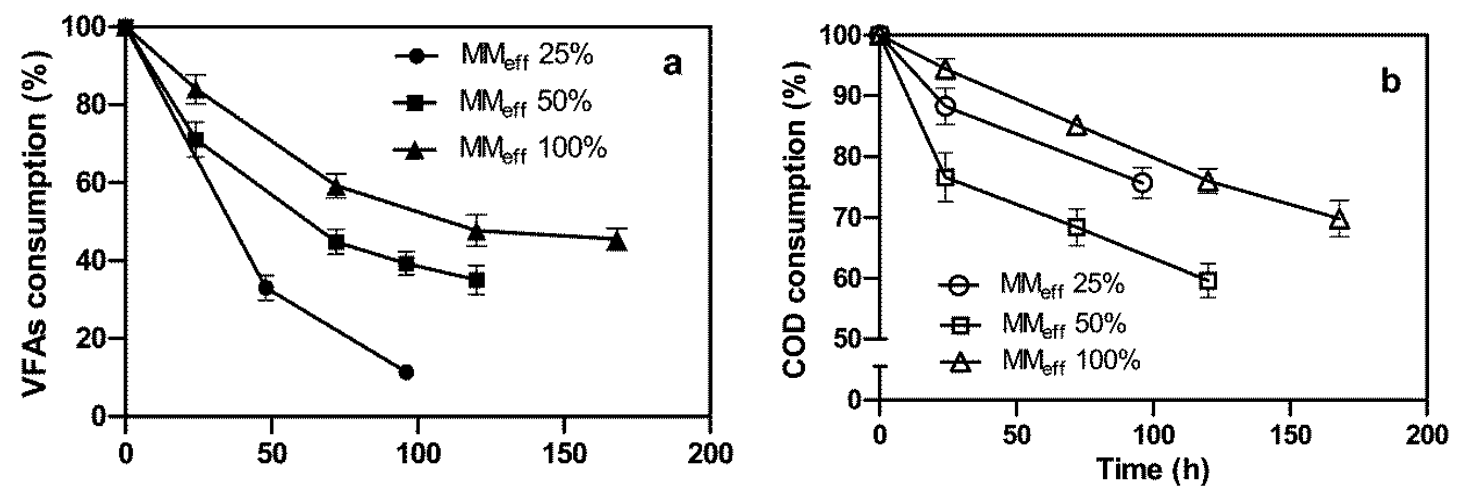

Figure 4. Consumption of COD and VFAs versus time during hydrogen photoevolution by means of R. palustris $\mathrm{sp}$. The photobioreactor was fed with undiluted MMeff or diluted MMeff with water (25\% and 50\%, v/v). (a) VFA consumption; (b) COD consumption.

These graphs demonstrated a very clear depletion of both the above-mentioned substances. By considering the amount of VFAs and COD as being equal to $100 \%$ at the start of the runs, it was noted that the higher the content of MMeff in the culture broth, the higher was the percentage of VFAs and COD in the exhausted broth at the end of the runs. In the case where the photobioreactor was fed with undiluted $\mathrm{MM}_{\text {eff }}$ and there was the addition of $0.65 \mathrm{~g} / \mathrm{L}$ of $\mathrm{NH}_{4} \mathrm{Cl}$, so that the nitrogenase was inhibited and no bioH$_{2}$ was produced, the cell metabolism was diverted towards biomass production, as shown in Figure 5.
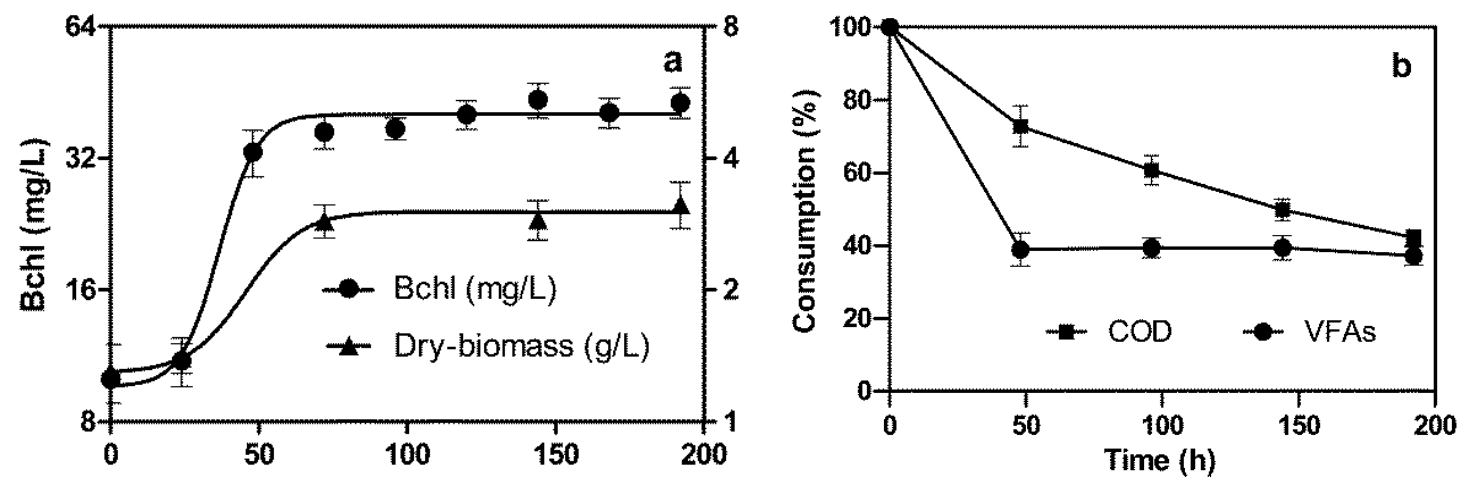

Figure 5. Batch growth of $R$. palustris sp. (a) and consumptions of the biocompounds (COD and VFAs) versus time (b). The photobioreactor was fed with undiluted $\mathrm{MM}_{\text {eff }}$ with the addition of $0.65 \mathrm{~g} / \mathrm{L}$ of $\mathrm{NH}_{4} \mathrm{Cl}$, in order to inhibit the nitrogenase and, consequently, the generation of hydrogen.

The Bchl concentration rapidly increased and reached a maximum value $(42.5 \mathrm{mg} / \mathrm{L})$. The highest value of the dry biomass concentration was $3.14 \mathrm{~g} / \mathrm{L}$, and the specific growth rate $\left(\mu_{\mathrm{e}}\right)$ was $0.0189 \mathrm{~h}^{-1}$. The consumption of both COD and VFAs was very rapid during the first 48 hours. In the following 
period, however, the COD concentration continued to decrease and reached the lowest value (42.2\%) at a culture age of 192 hours. By contrast, the consumption of VFAs ceased, and about 1/3 of its initial percentage eventually remained in the culture broth. This was probably due to the fact that some of the volatile acid compounds contained a high number of $\mathrm{C}$ atoms, such that $R$. palustris $\mathrm{sp}$. was not able to utilize them. Further investigations into this particular topic are in progress.

\section{Discussion}

Recently, a remarkable phenol removal of $76 \%$, almost comparable to that obtained in the present work, was obtained with a coagulation/flocculation process, by using a combination of an electrolyte $\left(\mathrm{Ca}(\mathrm{OH})_{2}\right)$ and a polyelectrolyte as polydiallyldimethylammonium chloride (PDADMAC) [26].

For some years now, synthetic VFA-rich media have been widely exploited for indoor and outdoor photofermentative bioH $_{2}$ production [27-29], and in particular, the use of VFA-rich wastes for producing hydrogen have been recently investigated by Fang et al. [30].

In a previous study, raw OMW was utilized for hydrogen photoproduction by Eroğlu et al. [4] using Rhodobacter sphaeroides O.U.001. Eroglu's group also carried out investigations of a clay pretreatment step for OMW, followed by photofermentation using the aforementioned microorganism. To perform these experiments, the volumetric ratio of either the pre-treated effluent or the raw OMW was kept constant at $4 \%(\mathrm{v} / \mathrm{v})$. Compared to photofermentation involving the use of raw OMW, the amount of photofermentative hydrogen production was doubled by exploiting the effluent of the clay pretreatment process. They attributed the improvements in hydrogen production to the depletion of color, which might have caused a shadowing effect on the photosynthetic bacterium, as well as to the sizeable removal of biodegradable compounds, such as phenols and some organic compounds. This latter effect is known to enhance photofermentative hydrogen production.

Properly concentrated effluent greatly reduces the final feedstock volume that has to be used for the photofermentative process of hydrogen production. On the contrary, highly diluted effluents can enormously increase the feedstock volumes that have to be converted into $\mathrm{bioH}_{2}$ using expensive photobioreactors. An environmental paradox could occur: instead of cleaning up the environment, clean fresh water would be contaminated. Compared to the previous OMW pretreatment studies reported elsewhere $[4,15]$, the prototype produced here for OMW dephenolization has the potential to reduce the amount of effluent that has to be fed to photobioreactors for $\mathrm{bioH}_{2}$ production.

An issue here is that photo-fermentation involves high costs and complex photobioreactors [21]. Some data relative to prices and costs for commercially available photobioreactors have been reported [31]. In addition, Basak et al. [20] noted that "the economy of $\mathrm{H}_{2}$ as an effective fuel depends on the costs related to production of $\mathrm{H}_{2}$, transportation of $\mathrm{H}_{2}$, fuel cells, storage of $\mathrm{H}_{2}$ and safety related issues". Thus, whatever the organism, the feedstock, the method and technique used, the ultimate goal is to produce $\mathrm{H}_{2}$ on a large scale at a price competitive with fossil fuels. In this regard, the cumulative hydrogen production, obtained in the present study by feeding the reactor with diluted $\mathrm{MM}_{\text {eff }}(50 \%, \mathrm{v} / \mathrm{v})$, was $23 \%$ greater than that which has previously been attained when feeding the photobioreactor with a carbon effluent diluted with water $(25 \%, \mathrm{v} / \mathrm{v})$ [15].

The practical application of the photofermentative hydrogen production has generally been limited by low feedstock conversion efficiency as discussed by Xie et al. [14]. These authors obtained maximum 
feedstock utilization for hydrogen production (31.87\%) at the hydraulic retention time (HRT) of 60 hours and an influent acetate concentration of $40 \mathrm{mM}$. Recently, a feedstock utilization of $49.83 \%$ was attained when feeding the reactor with malate [32]; the photobioreactor was operated under a semi-continuous regimen, at a HRT of 225 hours.

The regeneration tests of the adsorbent matrices, used in the present study, were not performed because PPs should be recovered since it has been shown to have incredible benefits for health. Batch desorption experiments for recovering PPs have already been carried out for Azolla and for GAC by our group [33]. Therefore, the dephenolization costs can be amortized and/or totally cancelled by the very high income of recovered phenols. In fact, it is known that biophenols affect the economic interests of pharmaceutical and cosmetic industries as far as biophenol compounds are concerned [34]. Although photo-fermentation involves high costs, complex photobioreactors, oxygen-intolerant photo-biological enzymes and rather low photosynthetic conversion efficiency [21,35], the bioconversion of OMW nevertheless remains an interesting process that needs to be further developed.

\section{Experimental Section}

\subsection{Experimental Design}

OMW was pretreated to remove the components that hinder the direct biological treatment of waste, especially PPs, using a new precommercial prototype developed at Institute of Ecosystem Study (ISE), section of Florence, National Research Council (CNR). Once the wastewater has been treated, a feedstock suitable for the photoproduction of biohydrogen by PNSB was obtained. With this process, it is possible to obtain also an oil-rich biomass. A schematic of the entire process is shown in Figure 6.

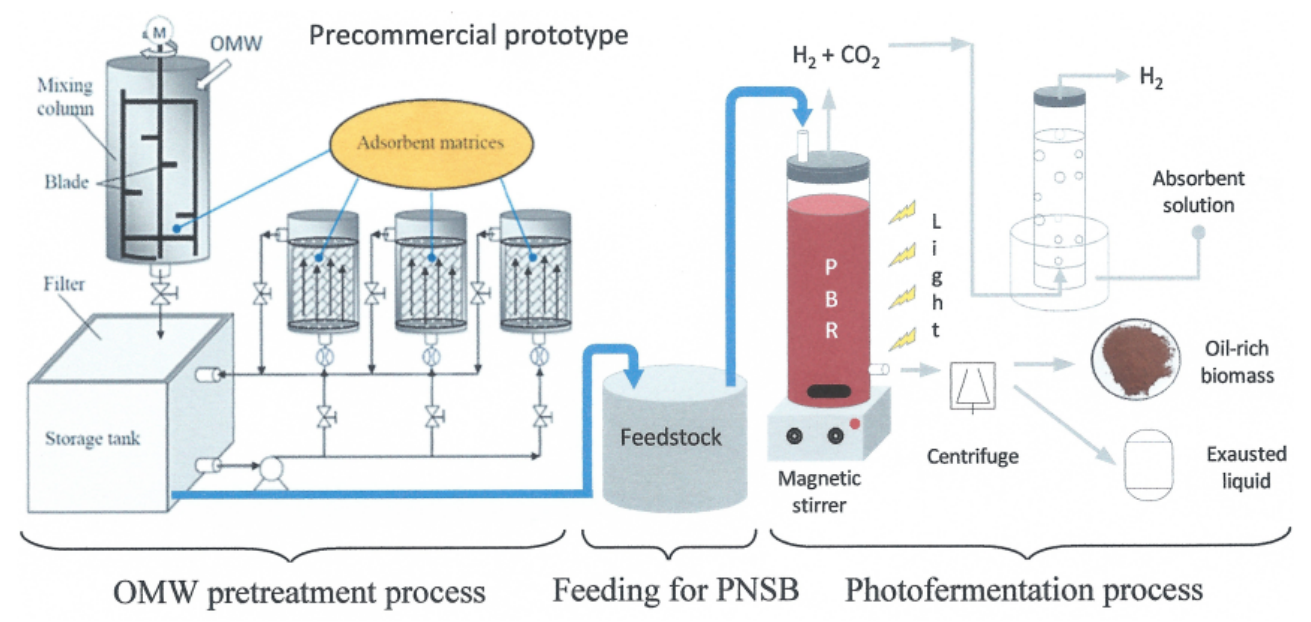

Figure 6. Schematic of the entire process.

\subsection{Olive-Mill Wastewater Pretreatment}

The OMW used came from an olive oil production company (Azienda Agricola Pruneti) located in San Polo in Chianti (Province of Florence), Italy. During the production season, fresh OMW was stored in an underground reservoir for a period of three months and was then collected and taken to be analyzed. 
The stored OMW was first centrifuged to remove suspended solids, and the liquid fraction was then used for the successive pretreatment process.

For the dephenolization of OMW, a device was created (Figure 1a), and a schematic of it is shown in Figure 1b. It consists of three main components: a mixing column with blades; three adsorbent columns and a storage tank with a filter ( $200 \mu \mathrm{m}$ of pore size) located on the upper side. All of the components of the device have an outer double wall through which a thermostatic liquid is circulated for controlling the working temperature of the system. The device has a maximum working volume of $200 \mathrm{~L}$. The flow of OMW inside each column was regulated by a water flow meter positioned at the bottom of the column, as shown in Figure 1.

The three different adsorbent matrices used simultaneously in the device were: GAC; Azolla (Az) and zeolite (Z). The GAC and Z matrices were provided by Carboplant srl (Vigevano, PV, Italy) while the Az matrix was produced, outdoors, on the premises of the olive oil producer (Azienda Agricola Pruneti), as shown in Figure 7.

The specific surface areas of the selected adsorbent matrices were the following: GAC $\left(1700 \mathrm{~m}^{2} / \mathrm{g}\right)$ and zeolite $\left(500-600 \mathrm{~m}^{2} / \mathrm{g}\right)$. The aquatic fern (Azolla) was used simply as a dried plant, without any grinding to provide for pulverization [15].

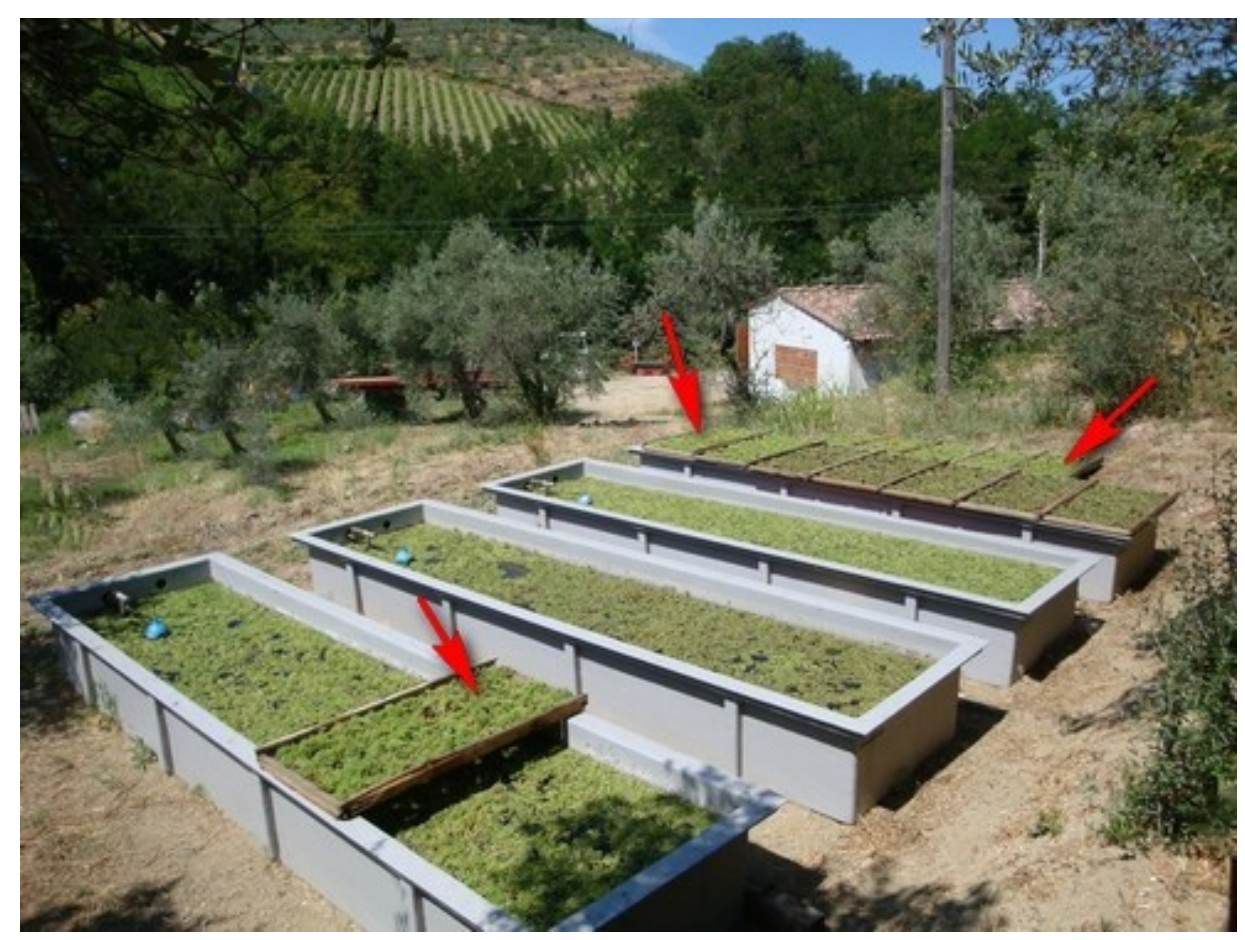

Figure 7. Experimental outdoor system for culturing the aquatic fern "Azolla" for use as a natural adsorbent matrix. The arrows indicate harvested Azolla biomass.

After centrifugation and acidification $(\mathrm{pH}=4.2), 100 \mathrm{~L}$ of stored OMW were placed inside the mixing column with blades, and $8 \mathrm{~kg}$ of GAC were then added. The mixture was stirred to guarantee maximal adsorption; after that, the mixture was discharged onto the (200 $\mu \mathrm{m}$ pore-size) filter positioned below the mixing column, and the GAC was separated from the resulting OMW-derived liquid that was collected in the storage tank (Figure 1). The pump for the circulation of the liquid was turned on (for 2 hours), and the GAC effluent (GAC eff) was pumped towards the first two columns of the device, which 
had been previously filled with $10 \mathrm{~kg}$ of $\mathrm{Az}$ and $10 \mathrm{~kg}$ of $\mathrm{Z}$, respectively. At the end of the entire sorbent process (a total of 4 hours), the multi-matrix effluent (MMeff) was collected and used as nutrients for feeding PNSB grown in a lab-scale photobioreactor, just for testing hydrogen generation.

\subsection{Compound Removal Efficiencies}

In order to determine the efficiency of the device during the synergic adsorption for various compound classes, a general equation was applied:

$$
R E(\%)=\frac{\mathrm{X}_{0}-\mathrm{X}_{f}}{\mathrm{X}_{0}} \mathrm{X} \times 100
$$

where RE is the removal efficiency of the specific compound of interest (PPs, COD, VFAs and color), $\mathrm{X}_{0}$ is the amount of each compound in the OMW before pretreatment and $\mathrm{X}_{\mathrm{f}}$ is the content of each compound in stored OMW after pretreatment using the device.

\subsection{Microorganism and Culture Operation Conditions}

R. palustris sp. is a rod-shaped phototrophic bacterium that reproduces by budding. It grows in a culture broth that contains organic compounds, such as acids, alcohols and aromatic substances, or in wastewaters rich in volatile acids [32]. R. palustris sp. was utilized here for the hydrogen production, using dephenolized OMW as feedstock. It was pre-cultured photo-heterotrophically in borosilicate glass bottles $(250 \mathrm{~mL})$, using the following medium composition (for a 1.0-litre volume): $2.0 \mathrm{~g} \mathrm{C}_{2} \mathrm{H}_{4} \mathrm{O}_{2}, 0.5 \mathrm{~g}$ $\mathrm{NH}_{4} \mathrm{Cl}, 1.0 \mathrm{~g} \mathrm{KH}_{2} \mathrm{PO}_{4}, 0.4 \mathrm{~g} \mathrm{NaCl}, 0.4 \mathrm{~g} \mathrm{MgSO}_{4} \cdot 7 \mathrm{H}_{2} \mathrm{O}, 0.05 \mathrm{~g} \mathrm{CaCl}_{2} \cdot 2 \mathrm{H}_{2} \mathrm{O}, 0.1 \mathrm{mg}$-aminobenzoic acid and $10 \mathrm{~mL}$ of mineral solution for micronutrients. The mineral solution $(1.0 \mathrm{~L})$ contained $1.0 \mathrm{mg}$ $\mathrm{CuCl}_{2} \cdot 2 \mathrm{H}_{2} \mathrm{O}, 2.0 \mathrm{mg} \mathrm{NiCl} 2 \cdot 6 \mathrm{H}_{2} \mathrm{O}, 3.0 \mathrm{mg} \mathrm{Ml_{2 }} \cdot 4 \mathrm{H}_{2} \mathrm{O}, 10 \mathrm{mg} \mathrm{ZnSO} \cdot 7 \mathrm{H}_{2} \mathrm{O}, 20 \mathrm{mg} \mathrm{CoCl} \cdot 6 \mathrm{H}_{2} \mathrm{O}, 30 \mathrm{mg}$ $\mathrm{H}_{3} \mathrm{BO}_{3}, 200 \mathrm{mg} \mathrm{FeSO} \cdot 7 \mathrm{H}_{2} \mathrm{O}$ and $500 \mathrm{mg} \mathrm{Na} \mathrm{MoO}_{4} \cdot 7 \mathrm{H}_{2} \mathrm{O}$. A fresh inoculum of $R$. palustris sp., growing in the aforementioned medium, was maintained by diluting the cultures twice a week before beginning the experiments using pretreated OMW. The investigation was carried out at a constant temperature of $30 \pm 0.2{ }^{\circ} \mathrm{C}$, under continuous light of $74 \mathrm{~W} / \mathrm{m}^{2}$.

The cylindrical glass photobioreactor (internal diameter $=4.0 \mathrm{~cm}$ ) used in the present study was placed in a heat exchanger Plexiglas water bath at a constant temperature. The culture was mixed by using a magnetic stirrer. The growth parameters (temperature and $\mathrm{pH}$ ) were monitored using probes connected to a control unit (Chemitec srl, Florence, Italy). The details about the schematic diagram of the cylindrical photobioreactor used for the investigation have been exhibited elsewhere [32]. All experiments were carried out in a thermostatic room and under atmospheric pressure. The gas produced by bacterial cells was first made to flow into a basin containing a $\mathrm{CO}_{2}$-absorber (saline solution of $\mathrm{NaOH}$ ), and hydrogen was then trapped in a calibrated column, where it was collected and the volume was measured in order to calculate the hydrogen production [15]. The calibrated column was refilled with a saline solution of $\mathrm{NaOH}$ every morning.

\subsection{Analytical Methods}

The pre-cultured $R$. palustris cells were collected by means of centrifugation and were washed with physiological solution to remove traces of synthetic salts. The cells were then suspended in the culture 
broths containing pure MMeff or diluted MMeff with water $(25 \%$ and $50 \% \mathrm{v} / \mathrm{v})$, in order to investigate the hydrogen evolution with the use of the above-mentioned photobioreactor. The initial $\mathrm{pH}$ of the cultures was 6.8, and this value was then maintained within the range of 6.8-7.2. All experiments were carried out under a continuous irradiance of $74 \mathrm{~W} / \mathrm{m}^{2}$, at $30 \pm 0.2{ }^{\circ} \mathrm{C}$, in batch growth conditions.

Padovani et al. [15] have recently investigated the bio-based technology for hydrogen photo-production by means of $R$. palustris sp. using wastewater as feedstock. They used stored OMW that had first been pre-treated with four different single-adsorbent matrices generating four different effluents, which were subsequently diluted with water $(25 \%, \mathrm{v} / \mathrm{v})$ and then used for producing $\mathrm{bioH}_{2}$. In the current study, the three selected adsorbent matrices (Az, GAC and Z) were combined in order to convert stored OMW into a single effluent, MMeff.

All reagents were acquired from Sigma Aldrich. A spectrophotometer Cary 50 (Agilent Technologies Inc., Santa Clara, CA, USA) was used for the following analyses. Bacteriochlorophyll (Bchl) amount and biomass dry weight were determined in accordance with Carlozzi et al. [36]. Polyphenols were determined in accordance with the method reported by Folin and Ciocalteu [37]. The total PP content was quantitatively determined at $730 \mathrm{~nm}$. The amount of volatile fatty acids (VFAs) was determined at $530 \mathrm{~nm}$. COD measurements were performed using a C99 Multiparameter Bench Photometer (HANNA, Lucca, Italy). Samples $(2 \mathrm{~mL})$ were added to an oxidizing chromatic acid solution and digested for 2 hours at $150{ }^{\circ} \mathrm{C}$; the measurements were carried out after cooling the samples. Color was determined measuring the absorbance (ABS) at $395 \mathrm{~nm}$ [38]. The $\mathrm{ABS}_{395}$ was measured in a 1-cm path-length of light using samples diluted to the ABS value of 0.10 to 1.0. Total lipid extraction was carried out by grinding $0.25 \mathrm{~g}$ of lyophilized bacterial cells in a mortar with sand and by extracting lipids for 24 hours with methanol:chloroform $(1: 2, \mathrm{v} / \mathrm{v})$ in a Paquot apparatus [39]. A rotary evaporator was used to remove the solvent completely, and the total lipid residue was determined after being dried at a constant weight.

A 150-W OSRAM power-star HQI-TS lamp was used to irradiate the culture; the irradiance was measured using a Quantum/Radiometer/Photometer (model LI-185B, LI-COR, Lincoln, NE, USA). The gas produced (with the $\mathrm{CO}_{2}$ having been removed by means of a saline solution of $\mathrm{NaOH}$ ) was trapped

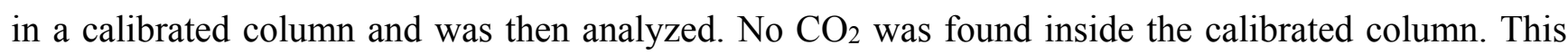
condition was controlled using a Perkin-Elmer Autosystem gas chromatograph equipped with a TCD detector and a Silica Gel 60/80 Grade 12 column (Alltech, Derfield, IL, USA). The carrier gas was helium, while known amounts of pure gases were used to calibrate the instrument. All analyses were carried out in triplicate \pm the standard deviation (SD).

\section{Conclusions}

The present work focused on OMW dephenolization by using a pre-commercial device to attain a $\mathrm{MM}_{\text {eff }}$ (feedstock) for $\mathrm{bioH}_{2}$ production. Photofermentation is a green biotechnology that can produce an energy vector from several wastewaters rich in organic nutrients. The MMeff was used either pure or diluted with water for feeding $R$. palustris. When feeding the photofermenter with diluted $\mathrm{MM}_{\mathrm{eff}}(50 \%, \mathrm{v} / \mathrm{v})$, the highest amount of $\mathrm{bioH}_{2}(1308 \mathrm{~mL} \mathrm{H} / \mathrm{L} \mathrm{MMeff})$ was obtained. This investigation showed some innovative features within a broader OMW bio-refinery process. Since the biomedical properties of PPs can be useful for the packaging, cosmetic and pharmaceutical markets, a complete OMW bio-refinery 
procedure could be combined with the technology for recovering bioactive compounds, such as PPs, for economic advantages.

\section{Acknowledgements}

This research was supported by the Ente Cassa di Risparmio di Firenze (Project No. 2013.0686) and Unità di Ricerca (UdR), Consorzio Interuniversitario Nazionale per la Scienza e la Tecnologia dei Materiali (INSTM) di Firenze and the project (Comunità Europea (CE) No. 1698/2005), Fondo Europeo Agricolo per lo Sviluppo Rurale (FEASR), Asse Leader Piano di Sviluppo Rurale 2007 to 2013, Regione Toscana-Misura 124-Bando, Gruppo di Azione Locale (GAL) Start. The authors wish to thank all of the team members of GAL-Start, Borgo S. Lorenzo, Tuscany, Italy, for providing necessary facilities and for supporting the above project (Misura 124). Many thanks also to olive oil production company Azienda Agricola PRUNETI, located in San Polo in Chianti (Florence), Italy, and all of the team members of Soluzione Ambiente Company, Tavarnuzze, Impruneta (Firenze), Italy.

\section{Author Contributions}

Pietro Carlozzi and Giulia Padovani designed the device and carried out the experiments. Giulia Padovani performed the analyses. Patrizia Cinelli and Andrea Lazzeri gave support for the interpretation of the results and for manuscript preparation. All of the authors contributed to writing the manuscript.

\section{Conflicts of Interest}

The authors declare no conflict of interest. The founding sponsors had no role in the design of the study; in the collection, analyses or interpretation of the data; in the writing of the manuscript; nor in the decision to publish the results.

\section{Abbreviations}

$\begin{array}{ll}\text { ABS } & \text { Absorbance } \\ \text { Az } & \text { Azolla } \\ \text { Bchl } & \text { Bacteriochlorophyll (mg/L) } \\ \text { COD } & \text { Chemical oxygen demand }(\mathrm{mg} / \mathrm{L}) \\ \text { Dw } & \text { Dry-weight }(\mathrm{g} / \mathrm{L}) \\ \text { GAC } & \text { Granular active carbon } \\ \text { GAC eff } & \text { GAC effluent } \\ \text { HPR } & \text { Hydrogen production rate }\left(\mathrm{mL} \mathrm{H}_{2} / \mathrm{L} \text { culture/h) }\right. \\ \text { MMeff } & \text { Multi-matrix effluent } \\ \text { OMW } & \text { Olive-mill wastewater } \\ \text { PHAs } & \text { Polyhydroxyalkanoates } \\ \text { PNSB } & \text { Purple non-sulfur photosynthetic bacteria } \\ \text { PPs } & \text { Polyphenols (g/L) } \\ \text { RE } & \text { Removal efficiency }(\%) \\ \text { VFAs } & \text { Volatile fatty acids }(\mathrm{mg} / \mathrm{L})\end{array}$




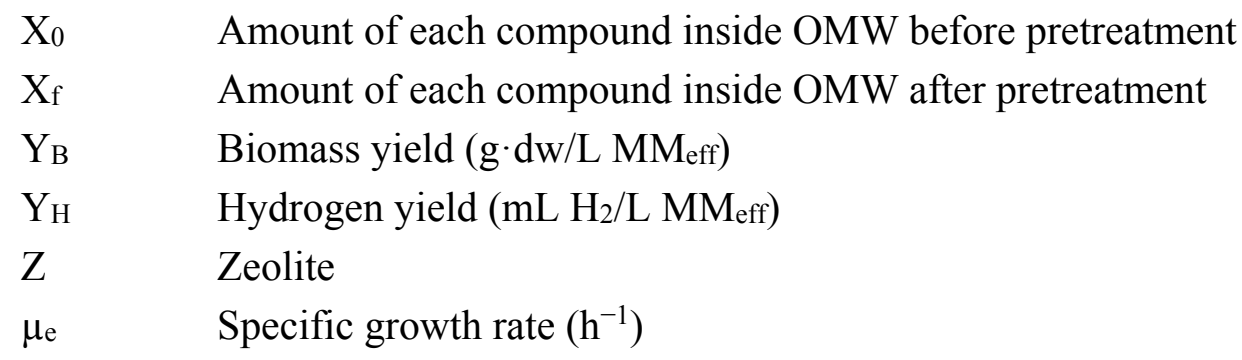

\section{References}

1. Keskin, T.; Abo-Hashesh, M.; Hallenbeck, P.C. Photofermentative hydrogen production from wastes. Bioresour. Technol. 2011, 102, 8557-8568.

2. Patel. S.K.S.; Kumar, P.; Kalia, V.C. Enhancing biological hydrogen production through complementary microbial metabolisms. Int. J. Hydrog. Energy 2012, 37, 10590-10603.

3. Eroğlu, E.; Eroğlu, I.; Gündüz, U.; Turker, L.; Yücel, M. Biological hydrogen production from olive mill wastewater with two-stage processes. Int. J. Hydrog. Energy 2006, 3, 1527-1535.

4. Eroğlu, E.; Eroğlu, I.; Gündüz, U.; Yücel, M. Effect of clay pretreatment on photofermentative hydrogen production from olive mill wastewater. Bioresour. Technol. 2008, 99, 6799-6808.

5. Pintucci, C.; Giovannelli, A.; Traversi, M.L.; Ena, A.; Padovani, G.; Carlozzi, P. Fresh olive mill waste deprived of polyphenols as feedstock for hydrogen photo-production by means of Rhodopseudomonas palustris 42OL. Renew. Energy 2013, 51, 358-363.

6. ElMekawy, A.; Diels, L.; Bertin, L.; De Wever, H.; Pant, D. Potential biovalorization techniques for olive mill biorefinery wastewater. Biofuels Bioprod. Biorefining 2014, 8, 283-293.

7. Hamdi, M. Future prospect and constraints of olive mill wastewater use and treatment: A review. Bioprocess Eng. 1993, 8, 209-214.

8. El Hajjouji, H.; Ait Baddi, G.; Yaacoubi, A.; Hamdi, H.; Winterton, P.; Revel, J.C.; Hafidi, M. Optimisation of biodegradation conditions for the treatment of olive mill wastewater. Bioresour. Technol. 2008, 99, 5505-5510.

9. Antizar-Ladislao, B.; Turrion-Gomez, J.L.; Second generation biofuels and local bio-energy systems. Biofuels Bioprod. Biorefining 2008, 2, 455-469.

10. Angelidaki, I.; Ahrin, B.K.; Deng, H.; Schmidt, J.E. Anaerobic digestion of olive oil mill effluents together with swine manure in UASB reactors. Water Sci. Technol. 2002, 45, 213-218.

11. Fezzani, B.; Cheikh, R.B. Two-phase anaerobic co-digestion of olive mill wastes in semi-continuous digesters at mesophilic temperature. Bioresour. Technol. 2010, 101, 1628-1634.

12. Ghosh, D.; Sobro, I.F.; Hallenbeck, P.C. Optimization of the hydrogen yield from single-stage photofermentation of glucose by Rhodobacter capsulatus JP91 using response surface methodology. Bioresour. Technol. 2012, 123, 199-206.

13. Liu, B.F.; Ren, N.Q.; Xing, D.F.; Ding, G.; Zheng, G.X.; Guo, W.Q.; Xu, J.F.; Xie, G.J. Hydrogen production by immobilized $R$. faecalis $\mathrm{RLD}-53$ using soluble metabolites from ethanol fermentation bacteria E. harbinense B49. Bioresour. Technol. 2009, 100, 2719-2723.

14. Xie, B.; Liu, F.; Ren, H.Y.; Xing, D.F.; Nan, J.; Ren, N.Q. Material flow analysis of feedstock for enhancing its conversion efficiency during continuous photo-hydrogen production. GCB Bioenergy 2013, 6, 621-628. 
15. Padovani, G.; Pintucci, C.; Carlozzi, P. Dephenolization of stored olive-mill wastewater, using four different adsorbing matrices to attain a low-cost feedstock for hydrogen photo-production. Bioresour. Technol. 2013, 138, 172-179.

16. Eroğlu, E.; Gündüz, U.; Yücel, M.; Turker, L.; Eroğlu, I. Photobiological hydrogen production by using olive mill wastewater as a sole substrate source. Int. J. Hydrog. Energy 2004, 29, 163-171.

17. Carraro, G.; Barreca, D.; Bekermann, D.; Montini, T.; Gasparotto, A.; Gombac, V.; Maccato, C.; Fornasiero, P. Supported F-doped $\alpha-\mathrm{Fe}_{2} \mathrm{O}_{3}$ nanomaterials: Synthesis, characterization and photo-assisted $\mathrm{H}_{2}$ production. J. Nanosci. Nanotechnol. 2013, 13, 4962-4968.

18. Hallenbeck, P.C.; Abo-Hashesh, M.; Ghosh, D. Strategies for improving biological hydrogen production. Bioresour. Technol. 2012, 110, 1-9.

19. Keskin, T.; Hallenbeck, P.C. Hydrogen production from sugar industry wastes using single-stage photofermentation. Bioresour. Technol. 2012, 112, 131-136.

20. Basak, N.; Jana, A.K.; Das, D.; Saikia, D. Photofermentative molecular biohydrogen production by purple-non-sulfur (PNS) bacteria in various modes: The present progress and future perspective. Int. J. Hydrog. Energy 2014, 39, 6853-6871.

21. Gupta, S.K.; Kumari, S.; Reddy, K.; Bux, F. Trends in biohydrogen production: Major challenges and state-of-the-art developments. Environ. Technol. 2013, 34, 1653-1670.

22. Hallenbeck, P.C.; Ghosh, D. Advances in fermentative biohydrogen production: The way forward? Trends Biotechnol. 2009, 27, 287-297.

23. Manish, S.; Banerjee, R. Comparison of biohydrogen production processes. Int. J. Hydrog. Energy 2008, 33, 279-286.

24. Redwood, M.D.; Beedle, M.P.; Macaskie, L.E. Integrating dark and light biohydrogen production strategies: Towards the hydrogen economy. Rev. Environ. Sci. Biotechnol. 2009, 8,149-185.

25. Achak, M.; Mandi, L.; Ouazzani, N. Removal of organic pollutants and nutrients from olive mill wastewater by a sand filter. J. Environ. Manag. 2009, 90, 2771-2779.

26. Iakovides, I.C.; Pantziaros, A.G.; Dimitris, P.; Zagklis, D.P.; Christakis, A.; Paraskeva, C.A. Effect of electrolytes/polyelectrolytes on the removal of solids and organics from olive mill wastewater. J. Chem. Technol. Biotechnol. 2014, doi: 10.1002/jctb.4563.

27. Shi, X.Y.; Yu, H.Q. Optimization of volatile fatty acid compositions for hydrogen production by Rhodopseudomonas capsulata. J. Chem. Technol. Biotechnol. 2005, 80, 1198-1203.

28. Carlozzi, P.; Lambardi, M.; Pushparaj, B.; Piccardi, R.; Sacchi, A. Indoor and outdoor photobiological hydrogen production by Rhodopseudomonas palustris, strain 42OL. Curr. Top. Biotechnol. 2008, 4, 93-100.

29. Chen, C.Y.; Lu, W.B.; Liu, C.H.; Chang, J.S. Improved phototrophic $\mathrm{H}_{2}$ production with Rhodopseudomonas palustris WP3-5 using acetate and butyrate as dual carbon substrates. Bioresour. Technol. 2008, 99, 3609-3616.

30. Fang, H.H.P.; Liu, H.; Zhang, T. Phototrophic hydrogen production from acetate and butyrate in wastewater. Int. J. Hydrog. Energy 2005, 30, 785-793.

31. PowerPlant CCS Report. A comprehensive report on emerging $\mathrm{CO}_{2}$ sequestration technologies at power plants. Available online: http://www.powerplantccs.com/ccs/cap/fut/alg/costs_of_pbr.html (accessed on 22 April 2015) 
32. Carlozzi, P. Hydrogen photoproduction by Rhodopseudomonas palustris 42OL cultured at high irradiance under a semicontinuous regime. J. Biomed. Biotechnol. 2012, doi:10.1155/2012/590693.

33. Ena, A.; Pintucci, C.; Carlozzi, P. The recovery of polyphenols from olive mill waste using two adsorbing vegetable matrices. J. Biotechnol. 2012, 157, 573-577.

34. Pintucci, C.; Padovani, G.; Giovannelli, A.; Traversi, M.L.; Ena, A.; Pushparaj, B.; Carlozzi, P. Hydrogen photo-evolution by Rhodopseudomonas palustris 6A using pre-treated olive mill wastewater and a synthetic medium containing sugars. Energy Convers. Manag. 2015, 90, 499-505.

35. Carlozzi, P. The effect of irradiance growing on hydrogen photoevolution and on the kinetic growth in Rhodopseudomonas palustris, strain 42OL. Int. J. Hydrog. Energy 2009, 34, 7949-7958.

36. Carlozzi, P.; Pushparaj, B.; Degl'Innocenti, A.; Capperucci, A. Growth characteristics of Rhodopseudomonas palustris cultured outdoors, in an underwater tubular photobioreactor and investigation on photosynthetic efficiency. Appl. Microbiol. Biotechnol. 2006, 73, 789-795.

37. Folin, O.; Ciocalteu, V. On tyrosine and tryptophan determination in proteins. J. Biol. Chem. 1927, $73,627-650$.

38. Fluori, F.; Sotirchos, D.; Ioannidou, S.; Balis, C. Decolorization of olive oil mill liquid wastes by chemical and biological means. Int. Biodeterior. Biodegrad. 1996, 38, 189-192.

39. Pham Quang, L.; Laur, M.H.; Paquot, C. A new method for lipid extraction and its use on two species of brown algae. Olèagineux 1970, 25, 223-225.

(C) 2015 by the authors; licensee MDPI, Basel, Switzerland. This article is an open access article distributed under the terms and conditions of the Creative Commons Attribution license (http://creativecommons.org/licenses/by/4.0/). 